RAE-IC, Revista de la Asociación Española de Investigación de la Comunicación vol. 8, núm. 15 (2021), 143-169 ISSN 2341-2690

Recibido el 21 de noviembre de 2020 DOI: https://doi.org/10.24137/raeic.8.15.7 Aceptado el 11 de diciembre de 2020

\title{
Design gráfico de livro para infância como forma de comunicação: quatro fases da produção brasileira
}

Children's picturebook graphic design as a form of communication: four phases of Brazilian production

Cavalcante de Almeida, Simone

Universidade Anhembi Morumbi (UAM-SP)

simonecavalcantee@gmail.com

Belluzzo de Campos, Gisela

Universidade Anhembi Morumbi (UAM-SP)

camposbelluzzo@gmail.com

Forma de citar este artículo:

Cavalcante de Almeida, S. y Belluzzo de Campos, G. (2021). Design gráfico de livro para infância como forma de comunicação: quatro fases da produção brasileira. RAE-IC, Revista de la Asociación Española de Investigación de la Comunicación, 8(15), 143-169. https://doi.org/10.24137/raeic.8.15.7

\section{Resumo:}

Este artigo propõe um breve painel de quatro fases de produção do design gráfico do livro para infância no Brasil. Explora estratégias formais, transformações culturais e mudanças tecnológicas que ampliam o potencial de comunicação dos livros a uma 
audiência massiva e urbana em crescente expansão. Partindo do estudo da argentina María del Valle Ledesma (2005) sobre a função de comunicação do design gráfico, os processos de concepção visual do design e da ilustração são relacionados à realidade ampla dos meios, aos sentidos de percepção e tipos de audiência das mensagens visuais, num intercruzamento entre a realidade do Brasil e do Ocidente. Os resultados alcançados demonstram os graus de experimentação, contradição e heterogeneidade da produção brasileira.

Palavras-chave: design, design gráfico, ilustração, livro para infância, comunicação, Brasil.

\section{Abstract:}

This article proposes a brief panel of four phases of production of the graphic design in the Brazilian children's picturebook. It explores formal strategies, cultural transformations and technological changes that have expand the communication potential of books to a massive and urban audience in growing expansion. Starting from the study of the Argentine María del Valle Ledesma (2005) on the communication function of graphic design, the processes of visual conception of design and illustration are related to the broad reality of the media, to the senses of perception and types of audience of visual messages, in an intersection between the reality of Brazil and the Western. The results achieved demonstrate the degrees of experimentation, contradiction and heterogeneity of Brazilian production.

Keywords: design, graphic design, illustration, children's picturebook, communication, Brazil.

\section{INTRODUÇÃO}

O livro para infância no Brasil vem se deparando com uma série de interferências culturais, socioeconômicas e tecnológicas, capazes de alterar a forma, a função e o potencial de significação de seu design gráfico. Os processos, métodos e técnicas de 
criação, os arranjos formais e as operações de materialização desses livros não são fixos no tempo, mas submetidos a um estado permanente de mudanças. Apresentar um painel das fases dessa produção no contexto de transformações dos meios de comunicação do ocidente é uma possibilidade de afirmar seu alcance comunicativo e valorizar seus traços diferenciais de experimentação, contradição e heterogeneidade.

Nesta perspectiva, o design gráfico passa a ser visto como uma forma de comunicação visual, sustentada por uma relação tripartite entre o sentido de percepção acessado pelos comunicantes, os meios, sejam manuscritos, impressos ou eletrônicos, e o caráter de seu contato com a audiência. Como uma forma particular de ordenar, regular e informar, as criações gráfico-visuais podem circular em diversos meios de comunicação. Possui um caráter social e coletivo, que abrange audiências da esfera pública e privada, espaços reduzidos, como âmbito familiar, ou mais amplos como o local, regional e internacional (Ledesma, 2005).

Apesar de sua trajetória secular, o design do livro para infância no Brasil é pouco explorado no conjunto de suas fases de produção. Entre as fontes antecedentes, as coletâneas Mestres da ilustração, organizada pelo ilustrador Jayme Cortez (1970), Catálogo ilustradores SIB: literatura infantil e juvenil (2008), A arte de ilustrar livros para crianças e jovens, organizado por Elizabeth Serra (2013), apresentam as trajetórias de ilustradores e designers em formato de biografia e portfólio. Os livros de memória gráfica - Linha do tempo do design gráfico no Brasil (2011), organizado pelos designers Chico Homem de Melo e Elaine Ramos, e A capa do livro brasileiro -1820-1950 (2017), de Ubiratan Machado-, situam algumas produções para infância.

A abordagem metodológica das relações entre design, ilustração e comunicação no livro para infância baseia-se numa leitura exploratória e bibliográfica. De modo geral, intercruza dados da realidade ocidental com a brasileira, situando livros impressos no contexto de surgimento de outras mídias, das variações do sentido de percepção e caráter da audiência. E de maneira específica, revisita a produção visual desses livros, a partir de quatro fases interdependentes, sinalizando suas principais transformações. 


\section{LIVRO NO CONTEXTO DE TRANSFORMAÇÕES DOS MEIOS}

Da escrita em pedras ou tábuas de argila, às folhas de papiro, passando pelo pergaminho de couro de animais e pelo códice, até alcançar o estágio de reprodução mecânica, com a invenção de Gutenberg, o livro vem acumulando um legado de técnicas, propósitos e aplicações de várias sociedades. No estágio de impressão, esse meio causou, com sua forma dobrada e encadernada, direcionada a uma escrita linear, um "procedimento de divórcio" entre tipografia e imagem, esvaziando as possibilidades abertas de leitura visual e "arborescência de conhecimento" dos manuscritos do final da Idade Média, com suas xilogravuras inscritas na superfície tabular (Melot, 2012). Como consequência, as imagens se submeteram a tentativas constantes de emancipação.

Ao longo dos tempos, o livro vem ocupando um lugar no quadro das demais invenções do mundo ocidental: escritura, imprensa, telégrafo, fotografia, rádio, TV e computador. Hoje, seja como objeto impresso ou desenvolvido por meio de software de programação, continua cumprindo o papel de veicular ideias, estando seu design direcionado a uma audiência massiva, conectado a redes telemáticas.

O livro e essas invenções são meios de comunicação, e seu funcionamento mantêm relação com um determinado sentido de percepção e tipo de audiência. O sentido de percepção compreende o trajeto pelo qual a mensagem circula entre receptores, envolve visão, gestual, oralidade, audição. O tipo de audiência ocorre de duas maneiras: quando somente duas pessoas se comunicam ou quando as informações alcançam ao mesmo tempo e massivamente muitas pessoas. A comunicação também se estabelece pessoalmente, e não apenas na relação com os aparatos técnicos. Os sentidos de percepção variam de hierarquia, com o surgimento de novas mídias e sua interferência no tipo de audiência. Mas o aparecimento de um meio não invalida a existência do outro, podendo haver entre eles graus diferentes de influência e aproximação (Ledesma, 2005).

Baseando-se em algumas relações entre os meios citados, sentido de percepção e caráter de audiência, elaborou-se um comparativo, nos Quadros 1 e 2, das principais mudanças pelas quais o livro e, por extensão, o livro para infância, atravessou na sua 
relação com outros meios. Um intercruzamento da realidade ocidental e brasileira, dentro de cenários estabelecidos a partir de diferentes processos de urbanização, industrialização e globalização.

Quadro 1. Transformações dos meios de comunicação no Ocidente

\begin{tabular}{|c|c|c|c|c|c|}
\hline Meio & Escritura & Imprensa & $\begin{array}{c}\text { Telégrafo e } \\
\text { Fotografia }\end{array}$ & Rádio e TV & Computador \\
\hline Contexto & $\begin{array}{l}\text { Até antes de } \\
1430 \\
\text { Oralidade das } \\
\text { línguas } \\
\text { predomina, } \\
\text { mesmo com a } \\
\text { presença da } \\
\text { escrita }\end{array}$ & $\begin{array}{c}\text { Século XV } \\
\text { Imprensa (1430) }\end{array}$ & $\begin{array}{c}\text { Século XIX } \\
\text { Telégrafo (1830) } \\
\text { Daguerreótipo } \\
\text { (1939) }\end{array}$ & $\begin{array}{l}\text { Primeiras } \\
\text { décadas do } \\
\text { século XX } \\
\text { Rádio (1901) } \\
\text { TV (1931) }\end{array}$ & $\begin{array}{l}\text { Metade do } \\
\text { século XX em } \\
\text { diante } \\
\text { Máquinas mais } \\
\text { industriais e } \\
\text { quarta geração } \\
\text { de } \\
\text { computadores }\end{array}$ \\
\hline $\begin{array}{l}\text { Sentido de } \\
\text { percepção }\end{array}$ & Oral & $\begin{array}{c}\text { Visual } \\
\text { Mais } \\
\text { preponderante } \\
\text { que a } \\
\text { oralidade das } \\
\text { línguas } \\
\text { Circulação de } \\
\text { livros } \\
\text { impressos } \\
\\
\text { Leitura } \\
\text { silenciosa } \\
\text { Primeiros } \\
\text { sinais da } \\
\text { comunicação } \\
\text { de massas }\end{array}$ & $\begin{array}{c}\text { Visual } \\
\text { Texto escrito e } \\
\text { imagem dividem } \\
\text { espaço } \\
\text { Surgimento da } \\
\text { comunicação de } \\
\text { massas (mass } \\
\text { media) nos moldes } \\
\text { de hoje }\end{array}$ & $\begin{array}{l}\text { Visual e oral } \\
\text { dividem } \\
\text { espaço }\end{array}$ & $\begin{array}{l}\text { Voz, audição } \\
\text { e visual se } \\
\text { confluem }\end{array}$ \\
\hline $\begin{array}{l}\text { Caráter da } \\
\text { Audiência }\end{array}$ & Interpessoal & Massiva & Massiva & Massiva & Massiva \\
\hline
\end{tabular}

Fonte: Elaboração das autoras, baseada na discussão teórica de Ledesma (2005). 
Quadro 2. Transformações dos meios de comunicação no Brasil

\begin{tabular}{|c|c|c|c|c|c|}
\hline Meio & Escritura & Imprensa & $\begin{array}{l}\text { Telégrafo e } \\
\text { Fotografia }\end{array}$ & Rádio e TV & Computador \\
\hline Contexto & $\begin{array}{l}\text { Até antes de } \\
1549 \\
\text { Sem a } \\
\text { circulação de } \\
\text { registros } \\
\text { escritos em } \\
\text { papel } \\
\text { Etnias } \\
\text { indígenas } \\
\text { ágrafas } \\
\text { Oralidade de } \\
\text { mitos e lendas } \\
\text { coexiste com } \\
\text { desenhos } \\
\text { rupestres }\end{array}$ & $\begin{array}{l}\text { Difusão de } \\
\text { repertórios } \\
\text { orais dos negros } \\
\text { (contadores de } \\
\text { histórias como } \\
\text { os akpalôs) } \\
\text { Presença dos } \\
\text { primeiros } \\
\text { escritos } \\
\text { Circulação de } \\
\text { livros religiosos } \\
\text { e profanos em } \\
\text { bibliotecas e } \\
\text { acervos } \\
\text { particulares, } \\
\text { importados da } \\
\text { Europa } \\
\text { Maioria da } \\
\text { população } \\
\text { analfabeta }\end{array}$ & $\begin{array}{l}\text { Início e fim do } \\
\text { monopólio da } \\
\text { Impressão Régia } \\
\text { (1808-1826) } \\
\text { Chegada do } \\
\text { daguerreótipo } \\
\text { (1839) } \\
\text { Implantação do } \\
\text { telégrafo (1852) } \\
\text { Surgimento de } \\
\text { tipografias e } \\
\text { litografias } \\
\text { Uso restrito de } \\
\text { fotografias nas } \\
\text { publicações } \\
\text { Início do } \\
\text { segmento do } \\
\text { livro para } \\
\text { infância }\end{array}$ & $\begin{array}{c}\text { Primeira } \\
\text { metade do } \\
\text { século XX } \\
\text { Expansão das } \\
\text { emissoras de } \\
\text { rádio e TV } \\
\text { Predominância } \\
\text { da ilustração } \\
\text { Presença de } \\
\text { escritores/as e } \\
\text { ilustradores/as } \\
\text { na mídia } \\
\text { Organização } \\
\text { política e } \\
\text { administrativa } \\
\text { do meio gráfico } \\
\text { e editorial }\end{array}$ & $\begin{array}{c}\text { Circulação intensa de } \\
\text { fotografia nas } \\
\text { publicações } \\
\text { Primeiras empresas } \\
\text { brasileiras de } \\
\text { computadores } \\
\text { (Cobra, 1976). } \\
\text { Chegada da Internet } \\
\text { no país (1988) } \\
\text { Surgimento de blogs, } \\
\text { sites, plataformas de } \\
\text { e-commerce } \\
\text { Expansão e } \\
\text { segmentação de } \\
\text { editoras } \\
\text { Aparição do livro } \\
\text { digital e outras mídias } \\
\text { interativas } \\
\text { Valorização conjunta } \\
\text { das ilustrações, } \\
\text { projeto gráfico e do } \\
\text { texto escrito no livro } \\
\text { para infância }\end{array}$ \\
\hline $\begin{array}{l}\text { Sentido de } \\
\text { percepção }\end{array}$ & Oral & Oral & $\begin{array}{l}\text { Texto escrito } \\
\text { tem mais } \\
\text { preponderância } \\
\text { que as imagens }\end{array}$ & $\begin{array}{c}\text { Visual e oral } \\
\text { dividem espaço } \\
\text { Auge da } \\
\text { comunicação de } \\
\text { massas }\end{array}$ & $\begin{array}{l}\text { Voz, audição e visual } \\
\text { confluem }\end{array}$ \\
\hline $\begin{array}{l}\text { Caráter da } \\
\text { Audiência }\end{array}$ & Interpessoal & $\begin{array}{c}\text { Interpessoal e } \\
\text { Massiva }\end{array}$ & Massiva & Massiva & Massiva \\
\hline
\end{tabular}

Fonte: Elaboração das autoras, baseada na discussão teórica de Ledesma (2005), Abreu (2010), Cardoso (2008), Arroyo (2011), Camargo (2003), Melo e Ramos (2011).

\section{ANTECEDENTES DO LIVRO PARA INFÂNCIA NO BRASIL}

Os primeiros indícios da tradição escriturária e da imprensa, no Brasil, aparecem, principalmente, com a circulação de documentos e obras importadas no início da colonização. Somente após a chegada da família real portuguesa, em 1808, dom João VI 
institui a Impressão Régia, a única imprensa autorizada a imprimir livros e documentações oficiais. Com o fim de seu monopólio, em 1821, casas publicadoras particulares multiplicam-se no Rio de Janeiro e se irradiam pela província (Camargo, 2003; Abreu, 2010).

Antes de o livro impresso tornar-se um dos principais meios de comunicar informações, histórias, poéticas, imagens, o Brasil já possuía uma riqueza de registros orais e visuais. No passado mais remoto, os desenhos rupestres que adornavam as paredes das cavernas, seguindo ou não fios narrativos, são as primeiras formas representativas de comunicação. Depois vieram as mitologias, lendas e histórias, provocadoras de imaginários e visualidades, transmitidas pela oralidade de indígenas nativos/as e negros/as trazidos da África para o trabalho escravo. Esses povos, de diferentes etnias, praticavam saberes, costumes e modos de falar distintos. Antes da chegada dos portugueses, estima-se a existência de 1078 línguas indígenas, como tupinambá (tupi antigo), kariri e manau, falados por nações dos grandes blocos: tupinambás e guaranis; e durante o processo de colonização, existiam línguas africanas do tronco linguístico banto -quicongo, quimbundo e Umbundo-, iorubás, minas-jejes (Rodrigues, 1993; Castro, 2020).

Nesse contexto, o sentido de percepção oral predominou durante três séculos, parte desse tempo, de maneira paralela ao caráter massivo da imprensa. Com a circulação dos primeiros livros e o aparecimento de novos meios de comunicação, o sentido oral, de audiência interpessoal, começa a sofrer forte concorrência do visual, muito associado à palavra escrita.

Os primeiros livros para infância desse período reproduzem um conjunto de valores conservadores, didático-moralizantes, que obscurecem grande parte da multiplicidade de códigos culturais (Gregorin Filho, 2009). As instâncias comunicativas do texto verbal e do design das produções privilegiam os costumes de uma classe emergente formada, sobretudo, por imigrantes brancos europeus, influentes no processo de exploração e formação sociocultural brasileira (Machado, 2017; Gregorin Filho, 2009). Dessas primeiras criações de design e ilustração até as que se encontram hoje em circulação, 
verifica-se o quanto elas carregam uma rede de códigos, símbolos, regras e interditos criados ou imaginados no meio sociocultural do qual fazem parte. Assim como reproduzem, emulam ou se apropriam de referências de outros contextos culturais.

Em termos visuais, a imitação de modelos importados de desenho, principalmente o geométrico; a cópia e reelaboração de gravuras publicadas anteriormente em edições estrangeiras; e a adoção de estilos gráficos europeus na composição do miolo e capa dos livros dificultam a expansão das abordagens visuais para a diversidade de formas e funções do design (Barbosa, 2015; Machado, 2017). Do ponto de vista da linguagem verbal, o discurso ficcional apresenta as primeiras simbioses entre os repertórios dos brancos com a tradição oral negra e indígena (Arroyo, 2011). Mas fatores como a escrita dominante em língua portuguesa e o reconto de temas da oralidade de procedência europeia servem de instrumento pedagógico para impor, nessa fase inicial, a visão cultural dos brancos (Gregorin Filho, 2009), diante da diversidade linguística e dos valores simbólicos dos diferentes povos habitantes do território brasileiro.

\section{DESIGN GRÁFICO DE LIVROS NO CENÁRIO DE PRODUÇÃO NACIONAL}

Os quadros comparativos entre o contexto ocidental e brasileiro servem de ponto de travessia para a apresentação de um painel com quatro fases de produção do design e das ilustrações do livro para infância. A partir deles, o livro pode ser relacionado com o sentido de percepção, audiência e elementos formais, culturais e tecnológicos determinantes.

Essa periodização tem como referência o levantamento realizado por Zilberman (2005) sobre a produção brasileira de livros para infância, do ponto de vista da escrita literária. No rastro de mudanças significativas na construção do texto escrito - abordagem do tema, construção de enredos, ponto de vista narrativo, relações entre espaço e tempo, cenários e personagens - ela situa os principais escritores e escritoras, a partir de sua habilidade em lidar com o discurso literário e os espaços de legitimação social de sua produção. 
Esta abordagem também toma como parâmetro a periodização dos contextos de tecnologia gráfica no Brasil, dividido em eras: da tipografia de chumbo, no século XIX; da ilustração, de 1900 a meados do século XX; da fotografia, nos meados do século XX aos anos 1980; e do digital, a partir dos anos 1990 (Melo e Ramos, 2011). A construção do design do livro para infância acompanha a maior parte dessas transformações tecnológicas, mas com um ritmo próprio, nem sempre coincidente com os marcadores temporais e as condições dessas eras.

Intercruzando a produção do livro para infância e o contexto da tecnologia gráfica, o design desses livros pode ser explorado em quatro períodos: Primeira fase - final do século XIX até 1920; Segunda fase-1920 até início de 1960; Terceira fase -final de 1960 até final de 1980; Quarta fase -1990 ao momento atual.

\subsection{PRIMEIRA FASE — FINAL DO SÉCULO XIX ATÉ 1920}

As oficinas gráficas existentes no Brasil, no século XIX, com seus maquinários de tipografia e clicheria, voltam-se à impressão de periódicos, como revistas e jornais. Após a instalação da Impressão Régia, há uma maior procura por processos avançados de reprodução de ilustrações, sendo empregadas, além da xilografia em madeira, técnicas como a litografia, o talho-doce, a fotogravura, que permitem o aumento da escala de impressão e a redução de custos (Cardoso, 2008; Camargo, 2003; Andrade, 2004).

Neste contexto, surgem os primeiros livros para infância, que apresentam muitas similaridades no seu design. Os projetos gráficos se assemelham tanto na diagramação como no emprego de tipografias, grid retangular, papel de baixa qualidade e dimensões aproximadas do miolo, entre $13 \times 18,5 \mathrm{~cm}$. As edições encadernadas em brochura e capa dura, são revestidas de percalina e decoradas com ornamentos. Elas contêm ilustrações em preto e branco e coloridas, com uso do desenho em bico de pena, xilogravura, aguada, água forte (Cardoso, 2005; Machado, 2017), que seguem, frequentemente, os padrões neoclássicos. A preponderância nos livros do texto escrito em relação às imagens induz o sentido de percepção visual a uma relação direta com a escrita. 
No período da Virada Industrial (1880 a 1920), o ensino da arte, nas escolas públicas, é compreendido como ensino do desenho, tendo o propósito de garantir a alfabetização formal da população e estimular suas habilidades para o trabalho nas atividades industriais, afinada com a ideologia do progresso técnico e do liberalismo econômico, com as correntes ideológicas do Positivismo e do Liberalismo (Barbosa, 2015). Como os títulos para infância dessa fase circulam no ambiente escolar, voltados à audiência de crianças, jovens e adultos, boa parte deles reproduz no seu visual essas ideologias.

As propostas das capas ainda adotam o padrão gráfico francês, discreto, bastante usado no livro para adultos. Há também uma recorrente utilização de imagens, jogos cromáticos e letras de estilo fantasia. O cultivo da sobriedade da capa, ainda presente, se apoia no receio das pessoas letradas de garantir a soberania do texto e se posicionar "contra o afloramento de uma cultura visual, considerada fútil, que deveria se limitar ao universo efêmero de revistas ou a livros de entretenimento e aprendizado, destinados ao público infantil” (Machado, 2017, p. 34).

O livro para infância logo se populariza com o investimento em edições avulsas e coleções, em grandes tiragens, como as famosas Coleção Biblioteca Infantil, da Quaresma, e Biblioteca Infantil Melhoramentos. Elas consagram escritores/as como Carlos Jansen, Olavo Bilac, Figueiredo Pimentel, a chamada tríade pioneira, Júlia Lopes de Almeida, Adelina Lopes Vieira, Presciliana Duarte de Almeida, e ilustradores como Julião Machado e Correia Dias. Diferente do texto verbal, a autoria das imagens raramente é mencionada.

Entre as características dessa produção, estão o atendimento a demandas de uma audiência massiva, concentrada nas escolas, a adaptação de obras estrangeiras e o reconto de histórias da tradição oral (Zilberman, 2005). Os livros Robinson Crusoé (1884), escrito por Carlos Jansen e ilustrado por W. Hoffmann, e Histórias da Avozinha (1896), de Figueiredo Pimentel com ilustrações de Julião Machado (Figura 1), são exemplos dessas abordagens. Os temas variam, mas os desenhos das personagens quase sempre aparecem caricaturados ou, algumas vezes, com traços que escapam à 
fisionomia da gente brasileira, com cenários também distanciados da cor local, como vistos na Figura 1.

Figura 1. Entre a cópia de modelos estrangeiros e a caricatura
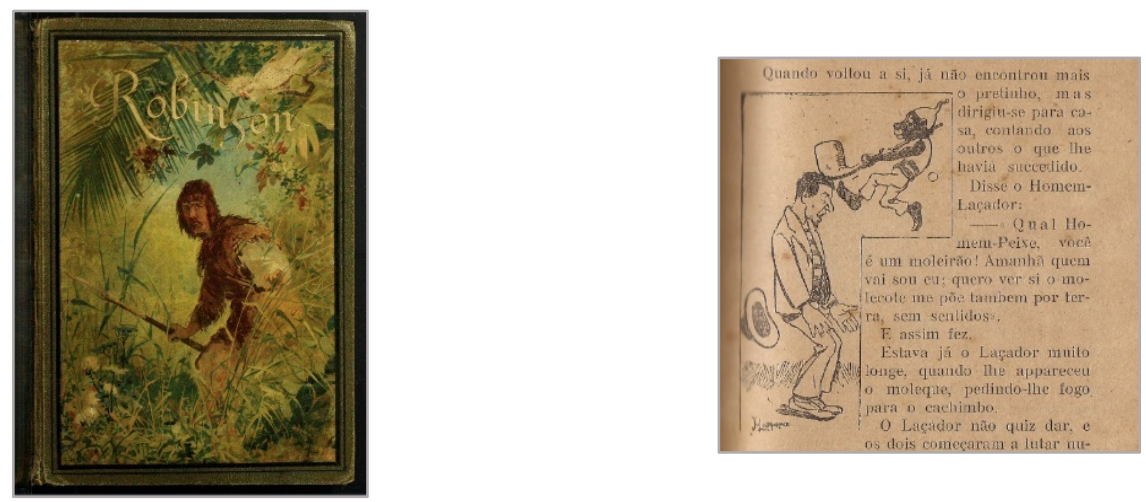

Fonte: Cópia de modelos estrangeiros em Robinson Crusoé. Jansen (1884), p. 17.

Acervo: Biblioteca Brasiliana Guita e José Mindlin (virtual). À esquerda. Ilustração caricaturada de Histórias da Avozinha. Pimentel (1926). Acervo pessoal. À direita.

\subsection{SEGUNDA FASE - 1920 ATÉ INÍCIO DE 1960}

De 1920 a metade dos anos 1960, o Brasil atravessa um intenso processo de industrialização e, por estar mais "integrado no mundo pelo progresso dos transportes e das comunicações, cresce a avidez por produtos de boa aparência" (Camargo, 2003, p. 89). O livro para infância, imerso no contexto dos meios massivos como a TV e o Rádio, alarga, como estes, sua malha de atuação no país, acompanhando também mudanças de mentalidade do setor gráfico-editorial. A busca por tecnologias e técnicas mais produtivas estimula a chegada da impressão offset, em 1922, a formação de uma mão de obra mais qualificada e a abertura aos investimentos de capital externo. Os incentivos públicos voltados à industrialização crescem aceleradamente.

As casas publicadoras se transformam em editoras especializadas em livros e algumas delas se estruturam no formato de sociedade anônima. Esse reordenamento colabora para consolidar a figura do editor como um dos principais mediadores do fluxo de desenvolvimento do livro. A presença de Monteiro Lobato, editor, escritor e dono da Cia. Editora Nacional (1926), será decisiva para a formação da cultura visual do livro para 
infância no Brasil. É ele quem sistematiza com soluções inovadoras algumas práticas em voga no meio editorial, como a distribuição de obras, o cuidado no seu tratamento visual e o uso da capa ilustrada e colorida com grande refinamento visual e abrangência comercial (Cardoso, 2005).

A atuação de Lobato tanto na escrita como no esmero de suas publicações desperta outras editoras, como Saraiva, Guanabara e Globo, de Porto Alegre, para investir no segmento de livros para infância. Surge assim uma leva de autores/as, antes voltados ao segmento adulto, que começam a produzir na área, como Érico Veríssimo e Graciliano Ramos. Destacam-se nessa fase também os escritores/as Maria José Dupré, Viriato Correia, Francisco Marins, Jerônimo Monteiro, e os ilustradores/as Acquarone, J. Carlos, Santa Rosa, Edgar Koetz e Dorca (Machado, 2017; Zilberman, 2005).

Embora o cientificismo da primeira fase ainda esteja presente, os temas dos livros se direcionam à exploração de contos da cultura popular. Há mais espaço para a narrativa de aventura, do antropomorfismo, personagens em forma de animal com comportamentos humanos, e de elementos ligados à realidade brasileira (Zilberman, 2015).

Grande parte das editoras usa como estratégia a definição de projetos gráficos arrojados para atender a demandas de uma audiência mais diversificada. Os segmentos do leitorado abarcam, além das escolas, espaços de sociabilidade e difusão literária, como as livrarias com suas vitrines aparelhadas e chamativas, os clubes de livros e as bibliotecas públicas infantis abertas pelo país, algumas delas explorando as primeiras iniciativas de círculos de leitura, a exemplo da Biblioteca Monteiro Lobato, na cidade de São Paulo (Machado, 2017; Camargo, 2003; Arroyo, 2011; Lobato, 1945).

Os livros impressos, agora em dimensões variadas, apresentam uma melhor distribuição entre textos escritos e imagens. As ilustrações, com marcas autorais, exploram criativamente a perspectiva, o ritmo, o movimento. O sentido de percepção visual ligado às imagens do design começa a equiparar-se, neste momento, à importância que vinha estabelecendo com a palavra escrita. 
Em O sapo Bonifácio (Figura 3), escrito por Adelina de Cerqueira Leite, a ilustradora Dorca utiliza a ilustração contínua na frente e no verso da capa, distanciando-se do padrão sisudo da primeira fase, assim como explora a página dupla e a dobra, que valorizam os elementos do cenário como a infinitude do céu, o movimento do lago e o gestual da personagem Bonifácio, conferido na Figura 2.

Figura 2. Elementos de design de O Sapo Bonifácio
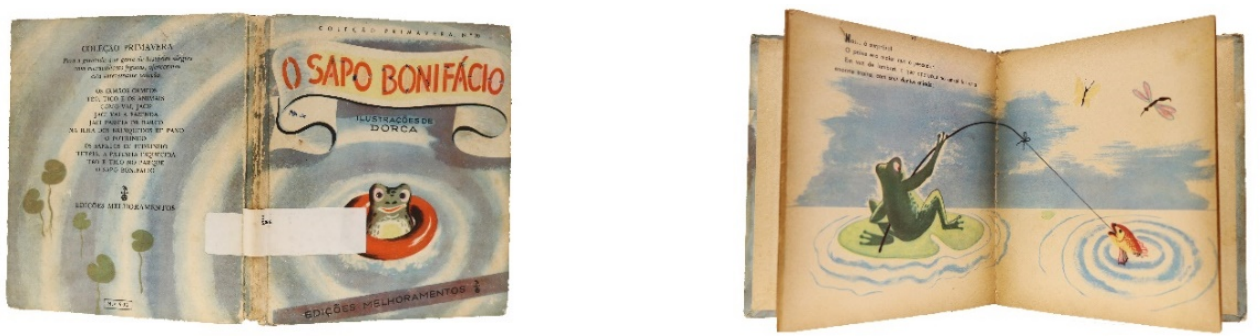

Fonte: Leite e Dorca (1951). Acervo Histórico do Livro Escolar (AHLE), Biblioteca Infantojuvenil Monteiro Lobato. Fotos das autoras.

\subsection{TERCEIRA FASE — FINAL DE 1960 A FINAL DE 1980}

Uma das mudanças tecnológicas decisivas da fase que vai do final dos anos 1960 ao final de 1980 é, sem dúvida, a incorporação dos processos automatizados no cotidiano de produção. As antigas prensas de tipografia e litografia, e a impressão offset, passam a dividir espaço com as máquinas modernas que chegam ao Brasil (Camargo, 2003). Em meio a dois momentos políticos influentes na história nacional - a ditadura militar e a reabertura política (1964-1985) - o setor assiste à preponderância de modelos industriais de produção em relação aos modos artesanais das artes gráficas, com a abertura de filiais pelo país, a consolidação de processos de fotolitagem numa abrangência industrial e os estímulos das iniciativas governamentais.

Ambos os setores gráfico e editorial recebem incentivos do Grupo Executivo da Indústria do Livro (GEIL), do Grupo Executivo das Indústrias de Papel e Artes Gráficas (GEIPAG) e do Instituto Nacional do Livro (INL). Os dois grupos, respectivamente, garantem às gráficas o financiamento para compra de papel e aquisição de máquinas importadas, enquanto o INL estimula o financiamento de coedições com grandes e pequenas editoras nas mais diferentes áreas. As grandes tiragens voltadas a uma audiência 
massiva tanto consolidam a circulação de livros nos espaços formais de educação como fomentam a estruturação de uma cadeia comercial - gráficas, editoras, distribuidoras, divulgadores e livrarias - próxima da realidade atual (Camargo, 2003).

Chegam ao mercado as primeiras máquinas de fotocomposição computadorizadas que agilizam os processos de produção e aumentam a qualidade de impressão das imagens. Os scanners de alta potência ampliam as possibilidades de experimentação do design gráfico. A oferta de uma diversidade de papéis, como offset e couché, garante uma melhor qualidade às publicações. Predominam as ilustrações em quatro cores, em cenários com fundos multicromáticos, como os dos livros da Figura 3: História meio ao contrário (1980), escrito por Ana Maria Machado e ilustrado por Humberto Guimarães, e Dudu Calunga (1986), de Joel Rufino, com ilustrações de José Flávio Teixeira. Esta última considerada uma das primeiras obras da literatura afro-brasileira.

Figura 3. Fundos multicromáticos empregados nos anos 1980
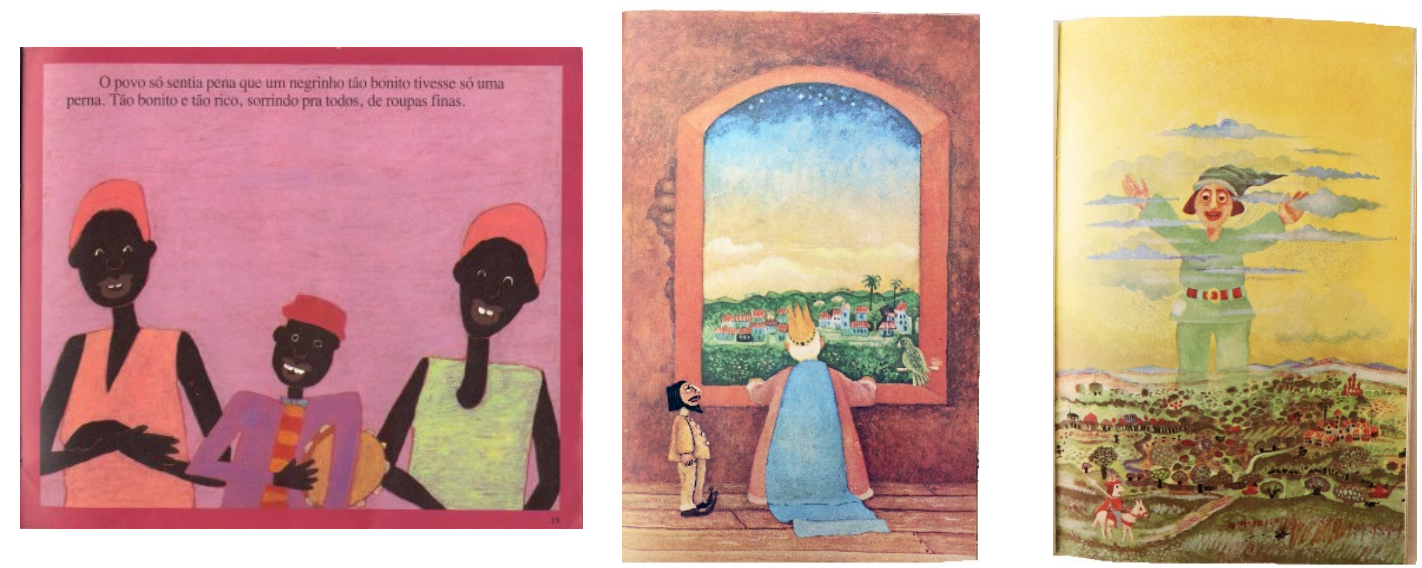

Fonte: Ilustração Dudu Calunga em papel couché. Rufino (1986). À esquerda.

Páginas ilustradas de História Meio ao contrário. Machado (1980).

À direita. Acervo Histórico do Livro Escolar (AHLE).

Em meio às restrições políticas da ditadura, os temas dos livros exploram os conflitos do mundo interior de personagens humanas, crianças em situação de rua, histórias do imaginário popular, e retomam as figuras de reis, rainhas, seres imaginários dos chamados contos de fadas, mas revelando suas fraquezas e rebeldias de modo a subverter essa tradição (Zilberman, 2005). 
Quanto ao sentido de percepção visual, a palavra escrita é percebida em igual importância às ilustrações e ao design da obra. É frequente o emprego sistemático do livro ilustrado, nos moldes atuais, e do livro-imagem, sem palavras impressas, assim como o uso do papel couché e a valorização das imagens no leiaute, algumas vezes com um intenso diálogo entre elementos da sintaxe visual e materialidade das obras. O livro ilustrado Flicts (1969), de Ziraldo, e os livros-imagem Ida e volta (1976), de Juarez Machado, e Outra vez (1984), de Angela Lago (Figura 6), são exemplos bem-sucedidos do casamento entre forma, conteúdo e materialidade, como se pode constatar na Figura 4.

Figura 4. Livros com preponderância da imagem
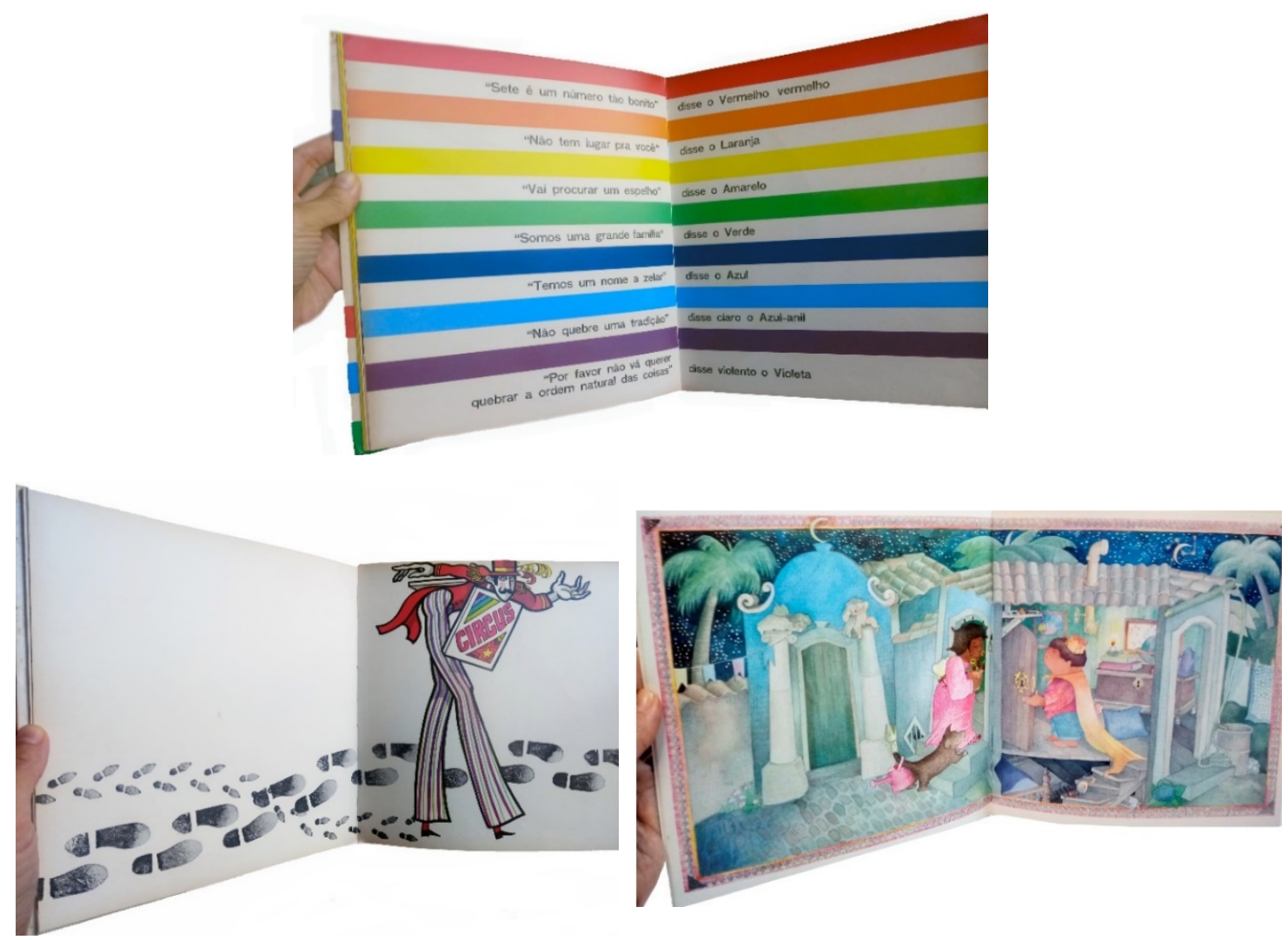

Fonte: Livro ilustrado Flicts. Ziraldo (1969), acima.

Livro-imagem Ida e volta. Machado (1976), à esquerda.

Livro-imagem Outra vez. Lago (1984), à direita. Fotos das autoras

O livro Flicts representa um divisor de águas entre esta fase e a anterior. Essa e outras obras de Ziraldo impulsionam a abertura do design de livros a uma diversidade de experimentações. Após essa publicação, "os artistas brasileiros expandem as fronteiras do livro ilustrado. Suas propostas não se restringem a modelos eurocêntricos e 
promovem uma descolonização visual, mesclando elementos globais e locais" (Mendes, 2016, p. 231). Dessa leva, fazem parte também ilustradores/as como Elvira Vigna, Eva Furnari, Gian Carli, Walter Ono, Eliardo França, José Flávio Teixeira, Humberto Guimarães, Paulo Von Poser.

A série Morená (1986), da ilustradora Ciça Fittipaldi, criada a partir de sua vivência com o povo Nambiquara, no Mato Grosso, estimula uma nova maneira de tratar a cultura indígena sem os estereótipos do passado. Seguida, na próxima fase, de livros para infância criados, pela primeira vez, pelos próprios indígenas, alguns contendo a grafia das línguas nativas. Histórias de índio (1996), escrito por Daniel Munduruku e ilustrado por Laurabeatriz, é considerada a primeira obra direcionada ao público infantojuvenil da chamada literatura indígena contemporânea (Giacomo, 2020).

Os projetos gráficos empregam leiautes e diagramações mais inventivas. Mas o diretor de arte da editora é ainda quem determina o espaço da página sobre o qual devem ser dispostas as ilustrações. Poucos profissionais com formação e noções de designer conseguem atuar de maneira autônoma (Lima, 1999).

O emprego de diagramas modulares ou sua ausência surgem como novas opções de composição. A página dupla se consolida agora com a aplicação recorrente de sangrias e a demarcação na forma gráfica de mudanças temporais e espaciais. É comum o uso diversificado de tipografias, ilustrações desenquadradas e dimensões variadas de formato em diálogo com o tema das histórias.

Com o uso da ficha técnica detalhada, as funções do design e da produção ficam evidenciados. A ficha traduz a divisão de trabalho do mundo industrial e parece responder ao critério de direitos autorais do programa de coedição do INL. Nela aparecem termos como projeto gráfico, diagramação, leiaute de capa, montagem, vinculados aos processos de construção do design.

\subsection{QUARTA FASE - 1990 AO MOMENTO ATUAL}

A quarta fase de produção começa nos anos 1990, com um ponto de virada para o século XXI e se estende até hoje. A popularização do computador e da Internet nos espaços de 
trabalho de designers e ilustradores/as possibilita a inserção dos profissionais numa rede globalizada de comunicação (Melo e Ramos, 2011). Neste contexto, muitas gráficas e editoras continuam funcionando em grande escala de produção, imprimindo em sistemas offset e rotogravura, e outras buscam a segmentação, utilizando sistemas de impressão por demanda, em processos digitais. Com a Internet, as editoras aderem ao e-commerce. O surgimento de plataformas digitais e dispositivos alteram os modelos de criação, configuração, gestão e circulação de conteúdos (Dick e Gonçalves, 2020).

A presença do computador gera uma nova demanda para o design, o desenvolvimento de interfaces gráficas, nas quais as imagens são acrescidas de movimento, som e efeitos especiais. A chegada do ebook, livro digital, e do livro-aplicativo, cria novos modelos de desenvolvimento das publicações, possibilita a separação entre suporte tecnológico e conteúdo e exige a atuação de uma gama de profissionais de outras áreas no cenário editorial (Dick e Gonçalves, 2020). Essas mídias ampliam o caráter massivo do livro para infância. Sua audiência, além do âmbito escolar e de comunidades leitoras, integra-se a uma rede ramificada, sem fronteiras territoriais. Nessa nova realidade, o operador de imagens é "uma espécie de demiurgo que prova, constrói numa velocidade instantânea formas que se transformam, coagulam-se, desagregam-se nas mãos de um deus impaciente que mancha e recria em sete segundos, e não em sete dias" (Ledesma, 2005, p. 78 , tradução nossa) $)^{1}$.

O livro digital coexiste com o livro impresso em papel. Sua presença alarga os suportes de leitura para telas de computador, tablets, smartphones e celulares, tendo consequências ainda incalculáveis. A menina do narizinho arrebitado (2007), de Monteiro Lobato, com ilustrações de Rogério Coelho, é considerada a primeira obra "efetivamente interativa, digital, multi e hipermidiática" do segmento para infância no Brasil (Lajolo e Zilberman, 2017, p. 18). Nessa nova realidade, "os lugares clássicos de escritor-leitor se pulverizam e, com eles, a própria relação de poder [entre palavra

\footnotetext{
${ }^{1}$ No espanhol: "uno especie de demiurgo que prueba, construye con la velocidad del instante formas que se transforman, se coagulan, se disgregan en manos de un dios impaciente que borronea y recrea en siete segundos y no en siete días."
} 
escrita e imagem] que tão trabalhosamente se construiu ao longo de séculos" (Ledesma, 2005$, p. 82$)^{2}$.

De outro lado, o domínio técnico de operações ampliado pelo computador proporciona uma conciliação sistemática dos processos de design. Torna-se recorrente a prática de uma mesma pessoa elaborar o texto escrito, o projeto gráfico e as ilustrações do livro, articulando procedimentos analógicos e digitais. O profissional passa a controlar operações antes restritas ao estágio de produção gráfica (Melo e Ramos, 2011).

O sentido de percepção visual do design, imagens e texto escrito do livro encontra um equilíbrio, algumas vezes com ênfase nas imagens. Mas gradualmente a confluência das formas perceptivas da voz e audição expandidas pelas interfaces gráficas do livro digital se intensificam. Ainda que isso ocorra numa espécie de revival de uma época remota na qual o sentido de percepção oral ocupava um lugar de preponderância (Ledesma, 2005).

Antes de 1990, o design gráfico é considerado somente uma atividade projetual que ordena num todo, de forma combinada, texto diagramado, elementos tipográficos, imagens, grafismos, com a finalidade de reprodução bidimensional, por meio gráfico (Villas-Boas, 2007). Após a chegada do computador e da Internet, essa forma de comunicação se amplia, com a possibilidade de reunir esses elementos anteriores em espaços quadridimensionais, como websites, sendo denominada de interface gráfica toda a manifestação do design gráfico em mídias que se movimentam (Campos, 2011).

Os processos de criação do design gráfico do livro para infância são enriquecidos pelo uso de sistemas de cores, programas de editoração eletrônica e ferramentas de desenho, como mesas digitalizadoras e bancos de imagens. Essas facilidades do mundo digital convivem com o analógico - cadernos de projetações, rafes e artes-finais-, numa miscelânea de procedimentos.

A alteração qualitativa na forma de comunicação desse design o diferencia, sobretudo, do contexto das primeiras fases. Há uma mudança na identidade do produtor. Antes ele

\footnotetext{
2 Versão original: "Los lugares clásicos de escritor-lector se pulverizan y, con ellos, la propia relación de poder que tan trabajosamente se construyó a lo largo de siglos".
} 
se confundia com um artista, vindo de áreas como a pintura; depois esse produtor conquista um estatuto próprio, ao assumir seu papel de design, alguns com formação universitária. A identidade desse produtor muda, à medida em que ele se desprende do trabalho de criação particular para ter uma noção de conjunto sobre um sistema de peças gráficas relacionadas a outros sistemas (Ledesma, 2005).

Atualmente, a produção do livro para infância alcançou um alto grau de diversificação. Tomando como representação dessa fase, Ricardo Azevedo, Marilda Castanha e Roger Mello, vemos o quanto suas produções prenunciam novos horizontes de inventividade do design.

Hoje os profissionais estão mais sintonizados com as possibilidades de combinação e diálogo entre elementos formais, culturais e tecnológicos. A formação em áreas como desenho industrial, artes plásticas, arquitetura e design gráfico está entre os fatores determinantes que ajudam a compreender essa mudança de cultura visual. Mesmo quando, no campo editorial, ainda persistem alguns traços conservadores, principalmente nas limitações de custos para inovação em materiais e acabamentos, isso não limita o experimentalismo gráfico-visual das produções.

As especificidades do design como forma de comunicação se definem pela ênfase numa consciência do fazer, quase universalizada; pelo alargamento das funções e possibilidades comunicativas tanto das imagens do projeto gráfico e da ilustração como da escrita verbal; pela introjeção da transversalidade cultural como tônica do processo de produção das imagens; e pela adoção da irreverência, surpresa, deslocamento e recusa de estereótipos e formas de controle.

Ao abordar temas da oralidade popular brasileira, Ricardo Azevedo, por exemplo, impregna de humor, encantamento e realismo fantástico os traços e cenários das ilustrações, realizando, a partir do emprego de diferentes técnicas, a quebra de expectativa da narrativa, como visto em seu livro Maria Gomes, na Figura 5. 
Figura 5. Ilustrações em página dupla do livro Maria Gomes
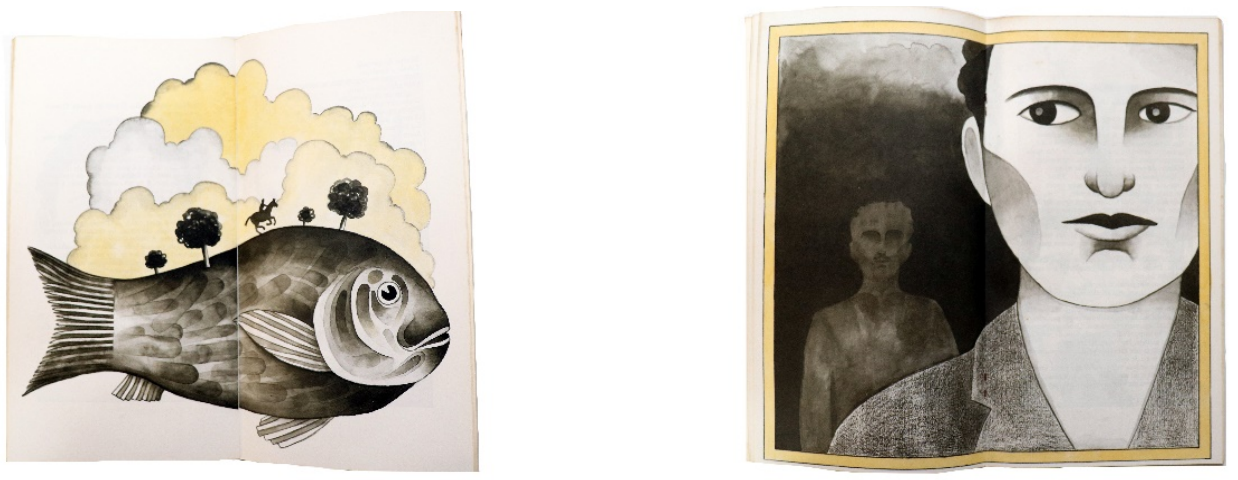

Fonte: Azevedo (1990). Acervo Histórico do Livro Escolar (AHLE).

A obra de Roger Mello explora todas as especificidades do momento atual. Em 2014, ele recebe o Prêmio Hans Christian Andersen, de ilustração, pelo conjunto de suas publicações, sinalizando positivamente as mudanças no design de livros brasileiros e sua projeção no cenário internacional. Nas imagens de 0 próximo dinossauro, Figura 6 , a perspectiva visual do livro se assemelha ao que, no cinema, é denominado de quebra da quarta parede. O leitor-espectador é convidado a interagir com a personagem, que imagina toda a história a partir de uma visita ao museu.

Figura 6. Perspectiva de construção visual de $O$ próximo dinossauro
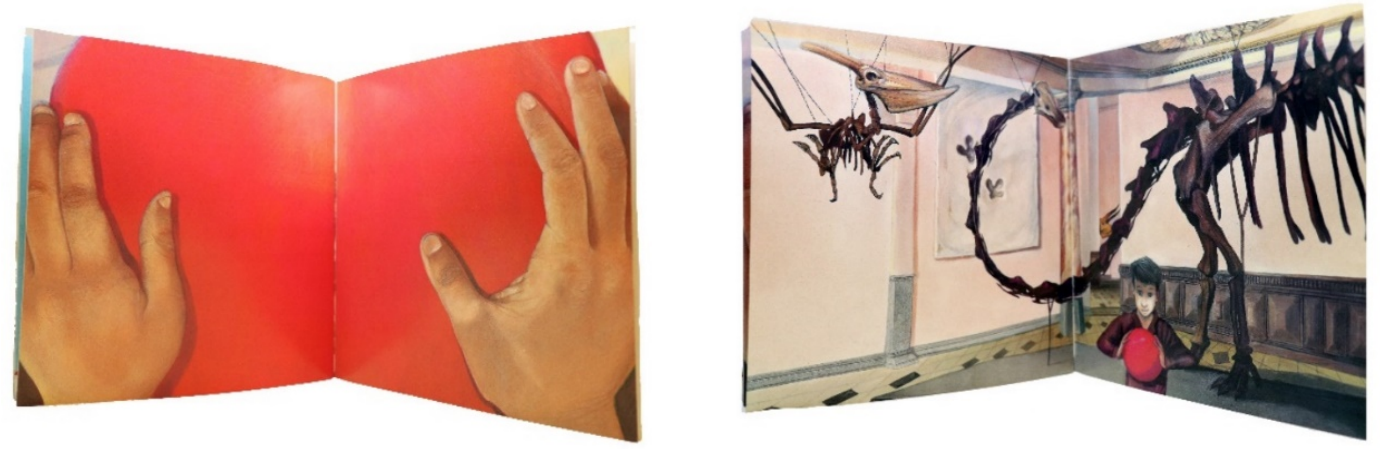

Fonte: Mello (1994). Acervo Histórico do Livro Escolar (AHLE).

As experimentações do visual de suas criações potencializam a forma comunicativa do design do livro, liberando as imagens para diferentes chaves de exploração e potencial de significados. O desenvolvimento de projetos, anos depois, como os livros-álbum João por um fio (2005) e Carvoeirinhos (2010), reafirma essa conexão orgânica entre os arranjos do projeto gráfico e as ilustrações, como revela a Figura 7. 
Figura 7. Páginas duplas de livros-álbum de Roger Mello
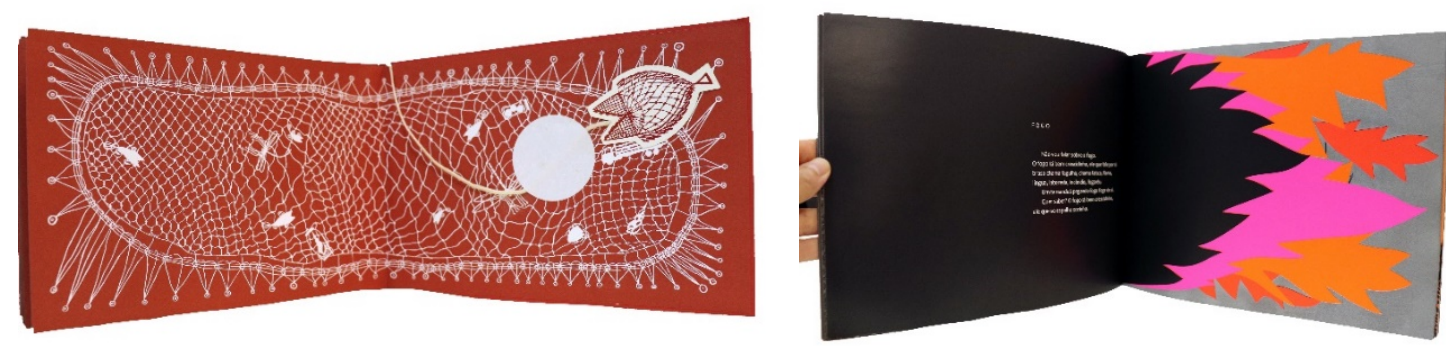

Fonte: João por um fio. Mello (2005). À esquerda.

Carvoeirinhos e (2009). Acervo Histórico do Livro Escolar (AHLE). À direita

Os trabalhos de Marilda Castanha exploram uma diversidade de temas, principalmente, da transversalidade cultural. A sua criação visual é construída em diferentes olhares, como visto na Figura 8. Suas imagens representam desde o universo particular da criança, como nas ilustrações de Joselito e seu esporte favorito (1996), escrita por Léo Cunha, até aspectos do meio ambiente e da cultura dos povos indígenas e africanos. Seu livro autoral Agbalá - um lugar-continente explora a trajetória dos negros no Brasil, reconfigurados na sua riqueza de formas e simbologias.

Figura 8. Diferentes olhares da ilustradora Marilda Castanha
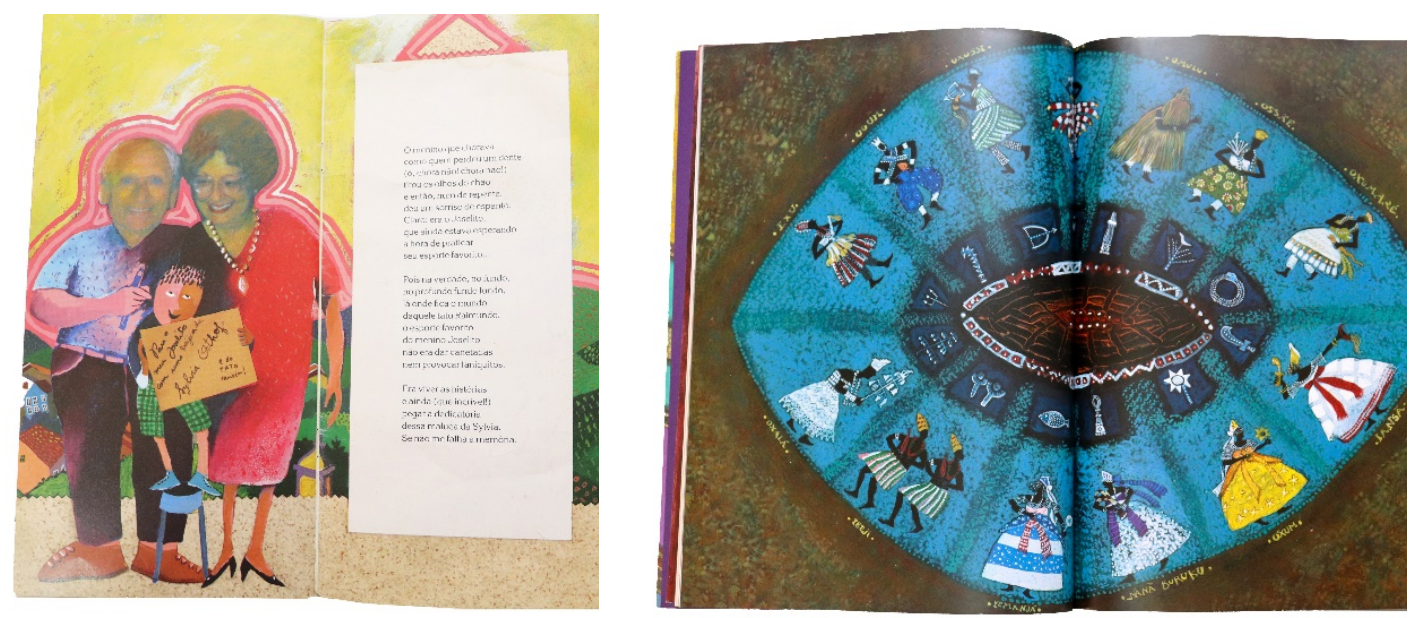

Fonte: Joselito e seu esporte favorito. Cunha e Castanha (1996). À esquerda. Agbalá. Castanha (2007). Acervo Histórico do Livro Escolar (AHLE). À direita. 


\section{CONSIDERAÇÕES FINAIS}

Este breve percurso do livro para infância no contexto de transformações dos meios revela como as interferências culturais, socieconômicas e tecnológicas influenciam as estratégias comunicativas de seu design. Isso repercute também no sentido de percepção. Ora o sentido visual se direciona à escrita, ora se volta tanto à escrita como à imagem, até chegar à confluência do visual, voz e audição, a partir da invenção do computador, da Internet e das demais mídias interativas.

Essas alternâncias no sentido da percepção se devem muito ao gradual protagonismo das ilustrações e projeto gráfico que, aos poucos, equiparam-se em importância aos códigos verbais. Isso vai se confirmando com o surgimento de novos tipos de livro ilustrado, nos moldes atuais, livro-imagem, livro-álbum. Estes se diferenciam dos livros com ilustração da primeira fase por reservar espaço maior para as imagens na espacialidade da página, e ampliar as possibilidades de articulação entre os aspectos formais, materiais e mecânicos do livro.

O design desse segmento, como forma de comunicação, voltou-se a uma audiência massiva e de caráter urbano, desde as primeiras publicações no século XIX até a atualidade. Inicialmente, essas produções destinavam-se ao segmento escolar mas, gradualmente, o perfil de audiência se alarga com a participação de novas comunidades leitoras, facilitada pelo acesso às plataformas digitais. A audiência massiva se mantém, mas suas funções de uso e alcance de significação se ampliam. Deslocando-se de significados que já estariam dados, fechados e claramente definidos, as estratégias de operação desse design tendem a causar "ambiguidade, confusão, ideologia, desejo e contradição" (Ledesma, 2005, p. 85, tradução nossa) ${ }^{3}$.

A partir deste painel, pode-se inferir três aspectos marcantes dessa produção: experimentação, contradição, heterogeneidade. Mesmo com o descompasso tecnológico da indústria gráfica nacional em relação a outros países do Ocidente, o processo de produção dessas imagens foi tomado, nas quatro fases, pela

\footnotetext{
${ }^{3}$ No original: “[...] ambigüedad, confusión, ideología, deseo y contradicción” [...].
} 
experimentação, inovação, singularidade, empreendidas tanto por iniciativa dos próprios agentes de criação, como pelo ímpeto de editores. Essas experimentações, ao empregar métodos, técnicas e procedimentos variados, contribuíram para a delimitação das especificidades gráficas do livro para infância e ampliação das "sinapses" comunicativas com os novos perfis de audiência.

Houve também algumas contradições. Na primeira fase, o livro para infância surge numa época de afrouxamento da censura da Impressão Régia, mas seu design e texto escrito se apresentam limitados a uma função reguladora e pedagógica; na segunda fase, mesmo com os saltos do contexto de tecnologia gráfica e dos arranjos visuais e verbais do período, os processos de design gráfico ainda estão obscurecidos pela supervalorização da ilustração; na terceira fase, diante da censura da ditadura, os profissionais da área parecem subverter a forma do livro, a exemplo do uso da sangria, do desenquadramento das ilustrações, da alternância de ritmo, das variações nas técnicas de montagem de textos e imagens. Na quarta fase, o computador e a Internet não provocam uma uniformização do fazer design, havendo uma convivência entre processos analógicos e digitais. Nem tampouco induzem a pasteurização da produção. O contato com realidades globais, ao contrário, estimula a "descolonização visual".

O fator heterogeneidade pode ser relacionado com as mudanças de estrutura, distribuição e função no processo de produção desse design. Em termos de estrutura, em cada uma das fases, diferentes condições materiais e invenções influenciam a busca por novos métodos, técnicas e procedimentos de criação, assim como amplificam a escala de reprodução, contribuindo com o aperfeiçoamento dos níveis de qualidade material e visual das obras.

Quanto à distribuição, o livro passa a circular em outros espaços de sociabilidade além das escolas, como bibliotecas, círculos de leitura, livrarias e nos ambientes virtuais.

No aspecto da função, o design desses livros teve, num primeiro momento, um papel pedagógico, controlador, e tal escolha se transpareceu até mesmo nos padrões repetitivos de elementos gráficos, como diagrama, dimensões da página, formato, 
leiaute. Da segunda fase em diante, o compromisso educativo se mantém, mas as preocupações normativas dividem espaço com outras funções do design.

Diante das alteridades dos contextos, designers e ilustradores/as criaram uma variedade de estratégias para estabelecer o design como forma de comunicação. "Em efeito, a incerteza constante, a complexidade da competência, a provisoriedade do valor simbólico de seus produtos, trazem como resultado a necessidade de uma constante exigência de variedade ${ }^{4}$ (Ledesma, 2005, p. 60, tradução nossa).

Os potenciais de comunicação do livro para infância no Brasil se demarcam no contexto das transformações dos meios. As inovações, rupturas e permanências da produção nacional a diferenciam das produções de outros países ocidentais. Sua singularidade se afirma na diversidade de caminhos visuais, ainda pouco explorados criticamente. Esta breve travessia se encerra com um convite para novos olhares e descobertas.

\section{REFERÊNCIAS BIBLIOGRÁFICAS}

Abreu, M. (2010). Duzentos anos: os primeiros livros brasileiros. Em A. Bragança e M. Abreu (Org.). Impresso no Brasil: dois séculos de livros brasileiros (pp.41-65). São Paulo: Editora da Unesp.

Andrade, J. M. F. de. (2004). História da fotorreportagem no Brasil: a fotografia na imprensa do Rio de Janeiro de 1839 a 1900. Rio de Janeiro: Elsevier.

Arroyo, L. (2011). Literatura infantil brasileira. São Paulo: Editora Unesp.

Azevedo, R. (1990). Maria Gomes. São Paulo: Scipione.

Barbosa, A. M. (2015). Redesenhando o desenho: educadores, política e história. São Paulo: Cortez.

Camargo, M. de (Org.). (2003). Gráfica: arte e indústria no Brasil - 180 anos de história. 2. ed. São Paulo: Bandeirantes Gráfica.

\footnotetext{
${ }^{4}$ Em espanhol: "En efecto, la incertidumbre constante, la complejidad de la competencia, la provisionalidad del valor simbólico de sus productos, traen como resultado la necesidad de una constante exigencia de variedad."
} 
Campos, G. B. de. (2011). Novos enfoques para o design gráfico. Em G. B. de Campos e M. Ledesma (Org.), Novas fronteiras do design gráfico (pp.27-40). São Paulo: Estação das Letras e Cores.

Cardoso, R. (2005). O design brasileiro antes do design: aspectos da história gráfica, 1870-1960. São Paulo: Cosac Naify.

Cardoso, R. (2008). Uma introdução à história do design. São Paulo: Blucher.

Castanha, M. (2007). Agbalá - um lugar-continente. São Paulo: Cosac Naify.

Castro, Y. P. de. (2020). Das línguas africanas ao português brasileiro. Recuperado de http://www.labjor.unicamp.br/patrimonio/materia.php?id=214_. Campinas (SP).

Cunha, L. e Castanha, M. (1996). Joselito e seu esporte favorito. Belo Horizonte: Miguilim.

Dick, M. E. e Gonçalves, B. S. (2020). Fatores que influenciam o processo de design do livro digital: uma investigação por meio de análise categorial. Revista Design \& tecnologia, 10(20), 106-118.

Giacomo, F. (2020). Breve história da literatura indígena contemporânea: pioneirismos. Recuperado de https://www.uol.com.br/ecoa/colunas/arte-fora-doscentros/2020/07/23/breve-historia-da-literatura-indigena-contemporaneapioneiros.htm

Gregorin Filho, J. N. (2009). Literatura infantil - múltiplas linguagens na formação de leitores. São Paulo: Melhoramentos.

Jansen, C. Robinson Crusoé. (1884). Biblioteca Brasiliana Guita e José Mindlin da Próreitoria de Cultura e Extensão Universitária da USP (São Paulo). Recuperado de https://digital.bbm.usp.br/simplesearch?query=robinson+cruso\%C3\%A9\&search=Buscar.

Lago, A. (1984). Outra vez. Belo Horizonte: Miguilim. 
Lajolo, M. e Zilberman, R. (2017). Literatura infantil brasileira - uma outra nova história. Curitiba: PUCPRESS.

Ledesma, M. del V. (2005). Diseño gráfico, un orden necesario? Em L. Arfuch, N. Chavez, e M. del V. Ledesma. Diseño y comunicación: teorías e enfoques críticos. Buenos Aires: Paidós.

Leite A. de C. e DORCA. (1951). O sapo Bonifácio. São Paulo: Edições Melhoramentos. Lima, G. (2000). O design gráfico do livro infantil no Brasil na década de 70 - Ziraldo, Eliardo e Gian Calvi (Dissertação de Mestrado em Design). PUC-Rio, Rio de Janeiro.

Lobato, M. (1945). Diálogo entre D. Benta e Narizinho sobre a Biblioteca de D. Lenyra e outras bibliotecas infantis. Revista Literatura e Arte, n. especial dedicado ao 1 으 Congresso Juvenil de Escritores e da 1ạ Exposição do Livro Infantil e Didático, São Paulo (SP), 28-31.

Machado, A. M. (1980). História meio ao contrário. São Paulo: Ática.

Machado, J. (1976). Ida e volta. Rio de Janeiro: Primor!

Machado, U. (2017). A capa do livro brasileiro 1820-1950. Cotia (SP): Ateliê Editorial; São Paulo: Sesi-SP Editora.

Melo, C. H. De e Ramos, E. (2011). Linha do tempo do design gráfico no Brasil. São Paulo: Cosac Naify.

Melot, M. (2012). Livro, Tradução: Marisa Midori Deaecto e Valéria Guimarães. Cotia (SP): Ateliê Editorial.

Mello, R. (1994). O próximo dinossauro. São Paulo: FTD.

Mello, R. (2005). João por um fio. São Paulo: Companhia das Letrinhas.

Mello, R. (2009). Carvoeirinhos. São Paulo: Companhia das Letrinhas.

Mendes, C. (2016). A descolonização das imagens: o livro ilustrado infantil no contexto brasileiro contemporâneo (Tese de Doutorado em Artes Visuais). UFRJ, Rio de Janeiro. 
Pimentel, F. (1926). Histórias da Avozinha. Rio de Janeiro: Quaresma.

Rodrigues, A. D. (1993). Línguas indígenas: 500 anos de descobertas e perdas. Delta, 9(1), 83-103.

Queirós, B. C. de (1979). Onde tem bruxa tem fada. Belo Horizonte: Vega.

Rufino, J. (1986). Dudu Calunga. São Paulo: Ática.

Villas-Boas, A. (2007). O que é [e o que nunca foi] design gráfico. Rio de Janeiro: 2AB.

Zilberman, R. (2005). Como e por que ler a literatura infantil brasileira. Rio de Janeiro: Objetiva.

Ziraldo. Flicts. (1969). Rio de Janeiro: Expressão e Cultura. 